7. Child Lang. 27 (2000), 393-406. Printed in the United Kingdom

(C) 2000 Cambridge University Press

\title{
NOTE
}

\section{Mothers' ability to identify infants' communicative acts consistently*}

\author{
DENIS MEADOWS, GORDON ELIAS AND JOHN BAIN \\ Griffith University, Faculty of Education \\ (Received 2 November I 998. Revised I Fuly I 999)
}

\begin{abstract}
A BSTRACT
A mother's ability to identify consistently what she perceives to be communicatively salient behaviours is considered to be fundamental to the process of responding sensitively to prelinguistic infants. The present study investigated the ability of 35 mothers to identify consistently what they perceived to be communicative acts by infants at three ages $(0 ; 6,0 ; 9$, and $\mathrm{I} ; 0)$. Each mother coded the same videotape of her infant's behaviour on two occasions, three months apart, and observed measures of agreement (consistency) between coded records were obtained. A randomization procedure was used to provide distributions of chance levels of agreement between coded records with which observed measures were compared. Comparisons of the mothers' coded records indicated that they were able to identify infants' communicative acts consistently at each age.
\end{abstract}

\section{INTRODUCTION}

Studies of preverbal infants during their everyday social interactions have revealed their striking abilities as communicators. It has been shown, for example, that even very young infants are sensitive to the prosodic patterns of their native language and are able to use such information to detect smaller and smaller units in the stream of speech (Jusczyk, Cutler \& Redanz, I993; McDonald, I 997). Further, as Adamson ( I 996) pointed out, biobehavioural shifts in the first few months of life result in other changes in infant behaviour (e.g. gaze behaviour, vocal behaviour and the ability to initiate actions) that 'transform the newborn into an engaging human communicator' (p. 92). During the course of the second half of their first year, infants develop the

[*] Address for correspondence: Gordon Elias, School of Cognition, Language and Special Education, Faculty of Education, Griffith University, Nathan, Queensland 4I II, Australia. e-mail: G.Elias@mailbox.gu.edu.au 
ability to coordinate their attention toward both a social partner and an external object (Corkum \& Moore, I998), and this ability to engage in joint attention provides a foundation for the shared experiences that underpin language acquisition (Butterworth, I 99 I, Tomasello, I 995).

While such changes in infants' abilities can be seen to markedly influence their development as communicators, mothers' responsiveness to their infants' behaviour has also been recognized as contributing to infants' communicative development (Ainsworth, Bell \& Stayton, I 974; Trevarthen, I 977; Ratner \& Bruner, I978; Snow, I98ı; Golinkoff, I983; Fogel \& Thelen, I987; Garton, I 992; Fogel, I993; Reed, I995; Elias \& Broerse, I 996). In this regard, it has been proposed that social contexts in which mothers select and respond to infants' non-verbal actions, for example, may play an important role in the emergence of pre-linguistic communicative signals such as gestures (Hoff-Ginsburg, I 987 ; Acredolo \& Goodwyn, I 988). The prelinguistic infant's use of a particular action to achieve an intended effect upon the partner is a major accomplishment (Wetherby, Cain, Yonclas \& Walker, I988; Mundy \& Gomes, I997), and a number of authors (e.g. Harding, I 983; Hopkins, I983; Camaioni, ı 989, г993) have emphasized that mothers' responses to their young infants' may assist infants to become aware of functional relationships between their own behaviours and those of their mothers.

Importantly, it has been proposed that mothers should provide consistent, contingent, and appropriate responses to those infant behaviours that they consider to be communicatively salient (Ainsworth et al., I974; Lamb \& Easterbrooks, I 98 I ; Rosenberg \& Robinson, I 988). Wilcox, Kouri \& Caswell ( I990) describe these pivotal aspects of maternal behaviour as features of 'partner sensitivity' (p. 679).

Clearly, a crucial step in this process of responding involves the mother's selection of actions from the infant's behavioural stream that might potentially act as signals (Adamson, Bakeman, Smith \& Walters, I987; Wilcox et al., I 990), and a first question to be asked is whether mothers can identify those acts in a consistent fashion. To what extent, for example, is a mother able to identify the same behaviours of her prelinguistic infant as communicatively salient on one occasion that she identified as salient on another occasion?

One way in which this issue may be investigated is by asking the mother to identify such actions from a videorecording of her infant's behaviour, and to compare her identification of those actions across a number of occasions. On each occasion, the infant actions that the mother perceives to be communicatively salient may be identified by providing her with a switch linked to a continuous event recorder and instructing her to press the switch while her infant is producing such a behaviour (Newtson, I973). By these means, a real-time record of the way in which the mother broke up (coded) 
the stream of her infant's behaviour into 'on' events (infant producing a communicatively salient action) and 'off' events (infant not producing a communicatively salient action) may be obtained for each occasion. This procedure avoids problems associated with requiring mothers 'to interrupt their observation of the ongoing behavioural stream' (Adamson et al., I 987 , p. $3_{3}$ ). These real-time records may then be compared to determine the extent to which the mother's identification of infant communicative acts was consistent across occasions.

The consistency with which mothers are able to identify their infants' communicative acts may be measured by comparison of the frequencies of 'on' (communicatively salient) events in the real-time records compiled on different occasions, for example (Wilcox et al., r 990). The difficulty with this measure, however, is that there is no surety that the infant behaviours coded by the mother on one occasion are the same as those coded on another. The frequencies on each occasion may be similar, but the infant behaviours to which they refer may be quite different. Consistency of selection implies that the behaviours selected as communicatively salient on one occasion are the same as those selected on another. (That is, it must be shown that the points at which the mother observes salient behaviours on one of her continuous records are the same as those occurring on another.)

Such difficulties associated with the use of frequencies of 'on' events to compare records may be avoided by comparing the ONSET times for each of the salient infant behaviours in the separate records. Adamson et al. ( 1987 ), for example, adopted this procedure in their investigation of the extent to which adults agreed upon infant behaviours that they perceived to be intentionally communicative or meaningful. These authors used a I second ( I-S) 'time-spread' in an attempt to take account of the partners' varying reaction times to the same infant act. (That is, onsets identified by different partners that occurred within the I-s spread were considered to refer to the same communicative act.)

However, while partners might differ markedly in terms of what they identify as the onset of a given infant communicative act ('on' event), thereby indicating no agreement according to Adamson et al.'s ( 1987) measure, they may show substantial agreement in terms of the communicative act ('on' event) TAKEN AS A WHOLE (i.e. from its start to its finish; Newtson, Engquist \& Bois, I977). Although there may be a difference of 2-s in the partners' identification of the onset of a particular communicative act, for example, there may be substantial agreement between the partners in terms of the remainder of that act: whilst not agreeing on the timing of the onset of an 'on' event, they may have agreed on its occurrence for 8-s of the remainder of that event. This difficulty applies equally when the onsets of communicative behaviours are used as a means of comparing two continuous records of a mother's coding of her infant's behaviour. Given this, it is 
proposed that measures of consistency should consider the WHOLE of each of the infants' acts identified as communicative and non-communicative; that is, the durations of the infant 'on' and 'off' events should be taken into account.

Using whole 'on' and 'off' events, measures of agreement between two continuous records can be obtained by comparing the records at each sampling point. At each sampling point, the records either agree (i.e. both 'on' at that point, or both 'off' at that point) or disagree (i.e. one 'on' and one 'off' at that point). A difficulty associated with measuring consistency between coded records when whole communicative acts are used, however, involves the determination of baseline ('chance') values of agreement. As has been pointed out, observed measures of agreement such as 'percentage agreement' are not meaningful In THEMSELves (Sackett, Rupenthal \& Gluck, I 978; Elias, Broerse, Hayes \& Jackson, I984; Elias \& Broerse, I996), and must be compared with those levels of agreement that might have occurred by chance.

Chance levels of agreement between the two records of her infant's behaviour, however, are affected by such factors as the frequencies and durations of the acts identified by the mother. The longer the durations of the communicative acts identified in each record, for example, the greater the likelihood that the records would agree on 'on' events by chance. Similarly, high levels of agreement might be obtained by chance if only a few (relatively brief) 'on' events were identified by the mother, even if these 'on' events did not occur at the same points in two records being compared. (In this case, the level of agreement would be high because of the general agreement on 'off' events between the two records.) One way in which these factors of frequency and duration may be taken into account is by the use of a randomization procedure in which the frequencies and durations of the communicative acts occurring in each record to be compared are used to calculate chance values of agreement (Elias et al., I 984; Elias \& Broerse, I996; Hayes, I 996).

Using this randomization procedure, two maternal records of the infant's behaviour may be compared. For each comparison, the observed records may be compared at each roo msec sampling point, for example, and an 'observed' level of agreement calculated. Next, for each comparison, the sequence of 'on' events and 'off' events in each of the two observed records is randomly permuted to produce 'randomized' records which may be compared at roo msec intervals to determine a level of agreement by chance. When this randomization procedure is carried out sooo times, a distribution of chance ('randomized') agreement values is generated which provides a direct means of estimating the likelihood of the observed level of agreement occurring by chance. An observed agreement value equal to, or greater than, the value that bounds the upper $5 \%$ of the randomized agreement distribution may be chosen, arbitrarily, as indicating a significant level of 
agreement, for example. The distribution of chance values generated by the randomization of the mother's two coded records is applicable to that comparison only, and directly reflects the frequencies and durations of the 'on' and 'off' events coded by the mother in the two records. (The randomization procedure must be employed for each and every comparison carried out so as to account for the frequencies and durations of the events in each of the records being compared.)

In the present investigation, the randomization procedure was used to determine mothers' ability to identify communicatively salient actions consistently in the behavioural streams of their prelinguistic infants aged between six months and one year.

METHOD

Subjects

Infant subjects and their mothers were recruited from the local community via newspaper articles and a radio interview by the investigators. A total of 45 mother-infant dyads was used in the study; 9 mothers with infants aged 0;6 (9 males and ro females), I 4 mothers with infants aged o; 9 (four males and Io females) and $\mathrm{I} 2$ mothers with infants aged I; 0 (six males and six females).

The dyads were divided into two groups, a main group and a control group. The main group of 35 dyads comprised 16 mothers with infants aged $0 ; 6$, I 2 with infants aged $0 ; 9$ and seven with infants aged $\mathrm{I} ; 0$. The remaining Io dyads formed the control group (three dyads with infants aged o; 6, 2 with infants aged $0 ; 9$ and 5 with infants aged $\mathrm{I} ; 0$ ).

\section{Procedure}

The preparation of stimulus videotapes. Videotaping of each mother-infant dyad in the main and control groups was carried out in an infant playroom and the mother was asked to interact with her infant as she would if she had 'a few free minutes at home'. The playroom was carpeted and contained lounge chairs and a low coffee table. During interaction, the mother and her infant were seated en face about ${ }^{\prime} \cdot 5$ metres apart. The mother sat in a lounge chair and the infant was seated in an infant car seat fixed to the top of the coffee table. ('This arrangement ensured that the partners' eyes were approximately level.) Two video cameras (remotely controlled from an adjoining room) were sited in opposite corners of the playroom and recorded mother and infant behaviours. A ceiling-mounted microphone provided audio input to the cameras. Input from both cameras (one focused on the mother and the other on the infant) was recorded simultaneously using a video mixer. The resulting video image showed the infant's face and body and contained a small insert of the mother's face and upper body in a top 
corner of the screen. The interaction between each mother and her infant was recorded for approximately i 5 minutes.

From this videotape, a stimulus videotape was prepared from which the sound of the mother's voice had been removed, and which included a 5 -min continuous segment of the interaction when it was 'going well' (i.e. the partners were monitoring/responding to each other's behaviour and the infant was not distressed or fussing). The beginning and end of this segment were marked by a $1000 \mathrm{~Hz}$ tone on the videotape so that repeated codings could be made of precisely the same portion of the tape. A I-min 'warm-up' segment was included at the beginning of each stimulus videotape.

The coding of stimulus tapes by mothers. Three weeks after the interaction had been videorecorded, the mother sat in a lounge chair in the playroom and reviewed the stimulus videotape of her infant. The insert containing the mother's image was covered on the television screen. The sound of the mother's voice had been removed from the videotape and her image was covered so that her coding of infant behaviour would not be influenced by the mother's awareness of own verbal and non-verbal behaviour as it occurred during the interaction (Hopkins, I983). When knowledge of her preceding and concurrent behaviours is available to the mother, such information may influence her classification of infant behaviour (Contole \& Over, I 979).

After previewing the videotape, the mother was asked to code her infant's behaviour during the next presentation by pressing a hand-held switch for the duration of those salient infant behaviours when she believed that her child was 'DELIBERATELY TRYING TO TELL [HER] SOMETHING OR DELIBERATELY TRYING TO GET [HER] TO DO SOMETHING'. Seated approximately $2 \mathrm{~m}$ behind the mother, an experimenter operated a MacLab to which the mother's switch was connected.

The mother began coding her infant's behaviour from the beginning of the stimulus videotape. Input from the mother's switch to the MacLab was not accepted, however, until the rooo $\mathrm{Hz}$ tone sounded signalling the onset of the selected 5-min segment. At the sound of the second tone (indicating the end of the selected segment), input from the mother's switch to the MacLab was discontinued. During the selected segment, the MacLab sampled the status of the mother's switch every roo ms and assigned a binary state ( I, 'on', a salient infant behaviour occurring; o, 'off', no salient infant behaviour occurring). In this way, a real time record of the mother's coding of the stream of her infant's behaviour was produced (coding I). The mother was requested to code her infant's behaviour once more, and a second real time record was produced (coding 2). Three months later, the mother previewed the stimulus videotape once more, and again coded her infant's behaviour twice (codings 3 and 4 ).

Unlike mothers in the main group who coded their infants' behaviour four times, control group mothers coded their infants' behaviour twice only. The 
control group was used to control for any practice effects of coding, and mothers in this group coded stimulus tapes of their infants' behaviour twice at a coding session conducted three months after their interactions had been videotaped. The coding sequences for main and control group mothers are shown in Fig. I.

\begin{tabular}{|c|c|c|}
\hline & \multicolumn{2}{|c|}{ Main group of mothers } \\
\hline \multirow[b]{2}{*}{$\begin{array}{l}\text { Time } \\
\text { Codings }\end{array}$} & Coding session I & Coding session 2 \\
\hline & $\begin{array}{c}3 \text { weeks after videotape } \\
\text { I \& } 2\end{array}$ & $\begin{array}{c}3 \text { months after session I } \\
3 \& 4\end{array}$ \\
\hline & \multicolumn{2}{|c|}{ Control group of mothers } \\
\hline & & Single coding session \\
\hline $\begin{array}{l}\text { Time } \\
\text { Codings }\end{array}$ & & $\begin{array}{c}3 \text { months after videotape } \\
\text { I \& } 2\end{array}$ \\
\hline
\end{tabular}

Fig. I. The coding of stimulus videotapes by main and control group mothers.

Measurement and randomization techniques. Figure 2 shows a section of a coded record created by sampling the status of the mother's coding switch every roo msec. At each sampling point, the record consists of one or other of two binary states, 'on' ( I ) or 'off' (o). Measurement of observed values of agreement between each mother's records (e.g. between coding I and coding 2) was carried out using dedicated software and involved determining whether the binary state in each of the two records agreed or disagreed at each sampling point. For each comparison of two records, the software calculated an Observed Agreement Ratio (OR; number of agreements on states divided by the number of agreements on states plus disagreements on states).

Sampling points at which the type of dyadic state changed were treated as EVENT boundaries, and all states between consecutive boundaries were treated as belonging to the same event. In the sequence of states shown in Figure 2, for example, there is an 'on' event (represented by the sequence of eleven 'I' states) bounded by 'off' states (represented by the 'o's). As indicated above, a randomization procedure was used to generate a distribution of 'chance' (baseline) values with which the OR could be compared, and this involved the reorganization of the events constituting the records. A software program randomly permuted the 'on' and 'off' events in each record (e.g. in codings 2 and 3 ), compared the binary states at each sampling 


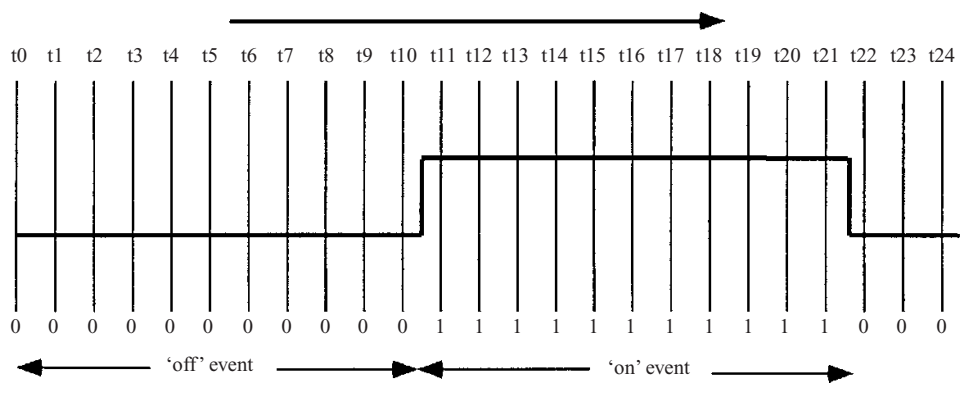

$0=$ 'off'

$0=$ 'on'

Fig. 2. States (os and Is) and events in a section of a coded record.

point, and calculated the Randomized Agreement Ratio (RR) in the same way as for the OR (i.e. number of agreements on states divided by the number of agreements on states plus disagreements on states). By performing I 000 iterations for each comparison, the programme produced a distribution of the 'chance' agreement values (Randomized Agreement Ratios) and calculated the probability of obtaining a value equal to, or less than, the OR from this distribution.

RESULTS

Three measures of each main group mother's ability to identify her infant's communicative acts consistently were obtained. The first involved comparing her codings made at the first coding session (i.e. within-session comparison of codings I \& 2), and the second involved comparison of her codings made at the second coding session (i.e. within-session comparison of codings $3 \&$ 4). Finally, to control for the possible effects of memory (recency) which might have influenced levels of agreement for within-session codings, the between-session comparison of codings 2 and 3 was carried out (i.e. codings separated by a 3 -month interval).

The control group mothers' ability to perform the task was investigated by comparing the two coded records compiled by each of these mothers at the single coding session conducted three months after the videorecording of their interactions. As indicated above, coding comparisons by this group of mothers were used to control for possible practice effects resulting from the main group mothers' multiple codings of the same stimulus videotape.

Table I shows descriptive statistics for the Observed Agreement Ratios (ORs) obtained for each pair of codings ( $1 \& 2,3 \& 4$ and $2 \& 3$ ) made by the mothers in the main group at each infant age. In addition, the Table indicates 
TABLE I. Mean observed agreement ratios and number of significant ORs as a function of coding comparisons and infant age (main group of mothers)

\begin{tabular}{|c|c|c|c|c|c|c|c|c|c|}
\hline & \multicolumn{9}{|c|}{ Codings } \\
\hline & \multicolumn{3}{|c|}{ I \& 2} & \multicolumn{3}{|c|}{$3 \& 4$} & \multicolumn{3}{|c|}{$2 \& 3$} \\
\hline & \multicolumn{3}{|c|}{ Age } & \multicolumn{3}{|c|}{ Age } & \multicolumn{3}{|c|}{ Age } \\
\hline & $\begin{array}{c}\circ ; 6 \\
(n=\mathrm{I} 6)\end{array}$ & $\begin{array}{c}0 ; 9 \\
(n=\mathrm{I} 2)\end{array}$ & $\begin{array}{c}\mathrm{I} ; 0 \\
(n=7)\end{array}$ & $\begin{array}{c}\circ ; 6 \\
(n=\mathrm{I} 6)\end{array}$ & $\begin{array}{c}\circ ; 9 \\
(n=\mathrm{I} 2)\end{array}$ & $\begin{array}{c}\mathrm{I} ; 6 \\
(n=7)\end{array}$ & $\begin{array}{c}\circ ; 6 \\
(n=\mathrm{I} 6)\end{array}$ & $\begin{array}{c}0 ; 9 \\
(n=\mathrm{I} 2)\end{array}$ & $\begin{array}{c}\mathrm{I} ; 0 \\
(n=7)\end{array}$ \\
\hline Minimium & 0.63 & 0.59 & 0.78 & 0.63 & 0.70 & 0.69 & $0.5 \mathrm{I}$ & 0.52 & 0.70 \\
\hline Maximum & 0.97 & 0.95 & 0.92 & 0.95 & 0.95 & $0.9 \mathrm{I}$ & 0.92 & 0.95 & 0.89 \\
\hline Mean & 0.83 & 0.83 & 0.85 & 0.86 & 0.84 & 0.80 & 0.80 & 0.77 & 0.80 \\
\hline S.D. & 0.09 & 0.12 & 0.05 & 0.08 & 0.09 & 0.09 & 0.12 & O. I 3 & 0.06 \\
\hline Significant $\mathrm{ORs}^{1}$ & I4 & 12 & 7 & I3 & 12 & 6 & I 2 & Io & 7 \\
\hline
\end{tabular}

1 ORs equal to, or greater than, the value bounding the upper $5 \%$ of the randomized distribution. 
the number of ORs at each infant age that were significant; those equal to, or greater than, the value which bounded the upper $5 \%$ of the randomized agreement distribution for each comparison.

\section{Within-session comparisons}

For the within-session comparison of codings I \& 2, the results of only two mothers failed to reach significance and each was the mother of an infant in the youngest group $(0 ; 6)$. When within-session codings $3 \& 4$ were compared, the results of only four mothers failed to reach significance, three being mothers of infants in the youngest group. It is clear from examination of Table I that, for each within-session comparison, there was a higher proportion of non-significant levels of agreement in the $0 ; 6$ age group compared with the $0 ; 9$ and $\mathrm{I} ; 0$ infants. Of a total of 32 within-session comparisons for the mothers of $\circ$; 6 infants, however, only five ( $16 \%$ ) failed to reach significant levels of agreement.

\section{Between-session comparisons}

When the possible effects of memory were controlled for (i.e. betweensession comparisons of codings 2 and 3), only 6 comparisons out of 35 ( $17 \%)$ failed to show significant levels of agreement across all infant ages. Of these six mothers, four were mothers of infants in the youngest group. Examination of the data for the between-session comparisons revealed that four of the six mothers whose codings failed to reach significant levels of agreement on that comparison reached significant levels of agreement on both of their withinsession comparisons. This suggests that there may have been a shift between the two coding sessions in those mothers' criteria for salient infant behaviours. Two of these mothers were mothers of infants aged $0 ; 6$, and two were mothers of infants aged $0 ; 9$.

Inspection of the data indicated that, across all infant ages and comparisons, the I2 comparisons which failed to reach significance were attributable to nine mothers, six of whom were mothers of infants in the youngest age group. The higher proportions of nonsignificant levels of agreement in both within- and between-session comparisons in the case of the $0 ; 6$ age group supports the view that these mothers may have had greater difficulty in identifying communicative acts in the behaviour of such young infants. Nevertheless, inspection of Table I reveals that the great majority of the mothers of these youngest infants were able to identify their infants' communicative acts consistently for each comparison carried out. Even in the between-session comparison (codings 2 and 3 ), $75 \%$ of the mothers of $0 ; 6$ infants were able to identify their infants' communicative acts consistently.

The overall picture emerging from the data is that the main group mothers at each infant age were able to identify consistently what they perceived to be communicative acts on the part of their infants. Of the total of 105 
TA ВLE 2. Descriptive statistics for observed agreement ratios and number of significant ORs as a function of infant age (control group of mothers)

\begin{tabular}{|c|c|c|c|}
\hline \multirow{2}{*}{$\begin{array}{l}\text { Coding comparison } \\
\text { Age }\end{array}$} & \multicolumn{3}{|c|}{ Codings I \& 2} \\
\hline & $\begin{array}{c}0 ; 6 \\
(n=3)\end{array}$ & $\begin{array}{c}0 ; 9 \\
(n=2)\end{array}$ & $\begin{array}{c}\mathrm{I} ; 0 \\
(n=5)\end{array}$ \\
\hline Minimum & 0.65 & 0.79 & 0.75 \\
\hline Maximum & 0.79 & 0.96 & 0.95 \\
\hline Mean & 0.71 & 0.12 & 0.08 \\
\hline$n$ Significant $\mathrm{ORs}^{1}$ & 3 & 2 & 5 \\
\hline
\end{tabular}

1 ORs equal to, or greater than, the value bounding the upper $5 \%$ of the randomized distribution.

comparisons involving these mothers, only i 2 ( I $\%$ ) failed to reach significance.

Table 2 shows descriptive statistics for ORs obtained for comparisons of the pairs of codings made by the control group mothers at each infant age. In no instance did the coding comparisons fail to reach significance (even at infant age $0 ; 6)$, suggesting that practice effects did not contribute substantially to mothers' ability to identify their infants' communicative acts consistently. When the main group and control group comparisons were combined across all infant ages, only i 2 out of I I 5 comparisons ( $10 \%$ ) did not reach significance.

\section{DISCUSSION}

Much research into early communication development has been dependent upon the observations of trained coders (Adamson et al., I 987). As Hopkins ( 1983, p. I36) proposed, however, researchers must somehow 'get into the head of the mother', also, if they are to understand how the shared code of communication emerges from the interactions of mothers and their infants. The purpose of the present study was to investigate aspects of the mother's behaviour as an interpreter of her infant's actions. More specifically, the aim was to determine whether mothers could identify what they considered to be communicative acts consistently.

The results indicate that, at each of the infant ages investigated, the mothers were able to do so. Of the I I 5 coding comparisons (main group plus control group mothers), only i 2 comparisons failed to reach significant levels of agreement. Even mothers of six-month-old infants were able to identify salient infant behaviours consistently. Although infants of this young age are generally not considered to be capable of intentional communication, these findings are consistent with the proposal that mothers of infants of this age impute intention to particular behaviours of their infants (Bates, Camaioni \& 
Volterra, I975; Harding, I983; Camaioni, I993). One reason for the relatively higher incidence of ORs that failed to reach significance in the $0 ; 6$ age group may be that mothers of these youngest infants experienced greater difficulties because of the unconventional nature of their infants' actions, and those actions' lack of definite perceptual boundaries (Adamson et al., I 987).

Even in the case of the comparisons with the highest incidence of nonsignificant levels of agreement (i.e. when a 3 -month interval separated the codings), only a few of the main group mothers failed to break up the stream of their infants' behaviour consistently. One reason why mothers might have been less successful under these conditions than in the within-session conditions involves possible changes in the mothers' criteria for salient infant actions over the 3-month interval. Given that their infants' communicative abilities would likely have changed over that relatively long period, it might well have been necessary for mothers at the second coding session to forgo their current criteria for what constituted salient communicative behaviours in favour of those that they had used three months earlier.

That is, the failure of some mothers to code their infants' behaviour consistently in the between-session condition may reflect their inability, or reluctance, to waive their current criteria in order to apply those that they had used earlier. In the case of the mothers of o; 6 infants, for example, at the mothers' second coding session 3 months later these infants would have been involved in the transition from non-intentional communicative acts to intentional communicative acts (Bates et al.'s ( I 975) transition from PERLOCUTIONARY to ILLOCUTIONARY stages). Given the emergent nature of these intentional communicative acts, mothers may have found it difficult to relinquish their current criteria in favour of those that they had used previously. Alternatively, the failure to code infant behaviour consistently over the 3-month interval might have resulted from mothers' misinterpretation of the instructions in that they assumed that they were to code their infants on the later occasion in terms of their infants' communicative abilities at that later time.

What the results of this investigation reveal is that the mother is capable of the initial step (consistent identification of salient infant behaviours) in the 'chain of responsivity' (Wilcox et al., i 990, p. 68 I). It must be recognized, however, that the fact that mothers were able to identify salient communicative acts consistently across sessions does not imply that this consistency NECESSARILY influences the child's communicative development. Further, as others (e.g. Adamson et al., I987; Wilcox et al., I990) have pointed out, although such findings indicate that the mother is capable of identifying salient infant acts consistently, the question as to whether the infant behaviours that she coded were those to which she, in fact, responded during the interaction remains unanswered. Clearly, this is an important issue that calls for further investigation. Investigation of the contingency and 


\section{IDENTIFYING INFANTS’ COMMUNICATIVE ACTS}

appropriateness of the mother's responses to the infant actions that she coded as salient should provide information to resolve this question.

\section{REFERENCES}

Acredolo, L. \& Goodwyn, S. ( 1988 ). Symbolic gesturing in normal infants. Child Development 59, $450-66$.

Adamson, L. B. (1996). Communication development during infancy. Madison, Wis: Westview. Adamson, L. B., Bakeman, R., Smith, C. B. \& Walters, A. S. (1987). Adults' interpretation of infants' acts. Developmental Psychology 23, 383-7.

Ainsworth, M. D. S., Bell, S. M. \& Stayton, D. S. (1974). Infant-mother attachment and social development: 'Socialization' as a product of reciprocal responsiveness to signals. In M. P. M. Richards (ed.), The integration of a child into a social world. London: Cambridge University Press.

Bates, E., Camaioni, L. \& Volterra, V. (I975). The acquisition of performatives prior to speech. Merrill-Palmer Quarterly 21, 205-26.

Butterworth, G. (I99I). The ontogeny and phylogeny of joint visual attention. In A. Whiten (ed.), Natural theories of mind: evolution, development, and simulation of everyday mindreading. Oxford: Blackwell.

Camaioni, L. (1989). The role of social interaction in the transition from communication to language. In A. de Ribaupierre (ed.), Transition mechanisms in child development: the longitudinal perspective. Cambridge: C.U.P.

Camaioni, L. (I993). The development of intentional communication: a re-analysis. In J. Nadel \& L. Camaioni (eds), New perspectives in early communicative development. London: Routledge.

Contole, J. \& Over, R. (I 979). Signal detection analysis of infant social behaviours. Fournal of Infant Behaviour and Development 2, $189-200$.

Corkum, V. \& Moore, C. (1 998). The origins of joint visual attention in infants. Developmental Psychology 34, 28-38.

Elias, G., Broerse, J., Hayes, A. \& Jackson, K. (1984). Comments on the use of conversational features in studies of the vocalization behaviours of mothers and infants. International Fournal of Behavioural Development 7, I77-9 I.

Elias, G. \& Broerse, J. (I996). Developmental changes in the incidence and likelihood of simultaneous talk during the first two years: a question of function. Fournal of Child Language 23, $20 \mathrm{I}-\mathrm{I} 7$.

Fogel, A. (1993). Two principles of communication: co-regulation and framing. In J. Nadel $\&$ L. Camaioni (eds), New perspectives in early communication. London: Routledge.

Fogel, A. \& Thelen, E. (1987). Development of early expressive and communicative action: reinterpreting the evidence from a dynamic systems perspective. Developmental Psychology 23, 747-6I.

Garton, A. F. (1992). Social interaction and the development of language and cognition. Hove: Erlbaum.

Golinkoff, R. M. ( 1983 ). The transition from prelinguistic to linguistic communication. Hillsdale, NJ : Erlbaum.

Harding, C. G. (1983). Setting the stage for language acquisition: communication in the first year. In R. M. Golinkoff (ed.), The transition from prelinguistic to linguistic communication. Hillsdale, NJ : Erlbaum.

Hayes, A. F. (I996). Permutation test is not distribution free. Testing $\mathrm{H}_{\mathrm{o}}: \mathrm{p}=$ o. Psychological Methods I, I 84-98.

Hoff-Ginsburg, E. (1987). Topic relations in mother-child conversation. First Language 7 , I $45^{-5} 5$.

Hopkins, B. (1983). The development of early non-verbal communication: an evaluation of its meaning. Fournal of Child Psychology and Psychiatry 24, I 3 I-44.

Jusczyk, P. W., Cutler, A. \& Redanz, L. (1993). Infants' sensitivity to predominant word stress patterns in English. Child Development 64, 675-87. 
Lamb, M. \& Easterbrooks, M. (I98I). Individual differences in parental sensitivity: origin, components, and consequences. In M. Lamb \& R. Sherrod (eds), Infant social cognition: empirical and theoretical considerations. Hillsdale, NJ: Erlbaum.

McDonald, J. L. (1997). Language acquisition: the acquisition of linguistic structure in normal and special populations. Annual Review of Psychology 48, 2 I 5-4I.

Mundy, P. \& Gomes, A. (I 997). A skills approach to early language development: lessons from research on developmental disabilities. In L. B. Adamson \& M. A. Romski (eds), Communication and language acquisition: discoveries from atypical development. Baltimore: Paul H. Brookes.

Newtson, D. (1973). Attribution and the unit of perception of ongoing behaviour. Fournal of Personality and Social Psychology 28, 28-38.

Newtson, D., Engquist, G. \& Bois, J. ( 1977). The objective basis of behaviour units. Fournal of Personality and Social Psychology 35, 847-62.

Ratner, N. \& Bruner, J. (1978). Games, social exchange and the acquisition of language. Fournal of Child Language 5, 391-402.

Reed, E. S. ( I 995). The ecological approach to language development: a radical solution to Chomsky's and Quine's problems. Language and Communication 15, I-29.

Rosenberg, S. \& Robinson, C. (1988). Interactions of parents with their young handicapped children. In S. Odom \& M. Karnes (eds), Early intervention for infants and children with handicaps. Baltimore: Paul H. Brooks.

Sackett, G. P., Ruppenthal, G. C. \& Gluck, J. (I978). Introduction: an overview of methodological and statistical problems in observational research. In G. P. Sackett (ed.), Observing behavior (vol. I): theory and applications in mental retardation. Baltimore: University Park Press.

Snow, C. (I98I). Social interaction and language acquisition. In P. Dale \& D. Ingram (eds), Child language: an international perspective. Baltimore: University Park Press.

Tomasello, M. (I 995). Joint attention as social cognition. In C. Moore \& P. J. Dunham (eds), Foint attention: its origins and role in development. Hillsdale, $\mathrm{NJ}$ : Erlbaum.

Trevarthen, C. (1977). Descriptive analyses of infant communicative behaviour. In H. R. Schaffer (ed.), Studies in mother-infant interaction. London: Academic Press.

Wetherby, A. M., Cain, D. H., Yonclas, D. G. \& Walker, V. G. (1988). Analysis of intentional communication of normal children from the prelinguistic to the multiword stage. Fournal of Speech and Hearing Research 31, 240-52.

Wilcox, M. J., Kouri, T. A. \& Caswell, S. ( I 990). Partner sensitivity to communication behaviour of young children with developmental disabilities. Fournal of Speech and Hearing Disorders 55, 679-93. 